\title{
Nursing Staff's Knowledge and Attitudes towards Dementia in an Indian Nursing Home: A Qualitative Interview Study
}

\author{
Benedicte Sørensen Strøm ${ }^{a}$ Hilde Lausund $^{a}$ Anne Marie Mork Rokstad ${ }^{b, c}$ \\ Knut Engedal ${ }^{c} \quad$ Alka Goyal $^{\mathrm{d}}$ \\ ${ }^{a}$ Faculty of Health Studies, VID Specialized University, Oslo, Norway; ${ }^{b}$ Faculty of Health Science and Social Care, \\ Molde University College, Molde, Norway; ${ }^{\mathrm{C}}$ Norwegian Advisory Unit for Aging and Health, Vestfold Hospital HF and \\ Department of Geriatrics, Oslo University Hospital, Tønsberg, Norway; ${ }^{d}$ Faculty of Health Sciences, Department of \\ Nursing and Health Promotion, Oslo Metropolitan University, Oslo, Norway
}

\section{Keywords}

Dementia $\cdot$ Attitude $\cdot$ Knowledge $\cdot$ India $\cdot$ Residential care

\begin{abstract}
Background: Despite the increased prevalence of dementia in India, there is reported to be little awareness of the disease. This could lead to a late diagnosis, a reduced number of choices regarding future care, and misinterpretation of the symptoms or neglect. Taking into consideration that most nurses caring for older people in the future will work with people with dementia, there is concern that they may not be able to meet the needs of this group of patients unless they have the necessary knowledge and a positive attitude. Aim: To explore the knowledge about and attitude towards dementia among nursing staff working in residential care facilities for older people in India. Method: An explorative and descriptive qualitative design was used. Two semistructured focus group interviews were conducted with nursing staff working in 6 nursing homes in India. Qualitative content analysis was used. Ethical approval was granted by the Norwegian Social Science Data Services. Findings: The participants highlighted the following 3 dimensions in rela-
\end{abstract}

karger@karger.com www.karger.com/dee

Karger $\stackrel{\text { ' }}{5}$

BOPEN ACCESS
(C) 2021 The Author(s)

Published by S. Karger AG, Basel

This article is licensed under the Creative Commons AttributionNonCommercial-NoDerivatives 4.0 International License (CC BY NC-ND) (http://www.karger.com/Services/OpenAccessLicense) Usage and distribution for commercial purposes as well as any distribution of modified material requires written permission. tion to their knowledge of and attitudes toward dementia in residential care facilities in India: (1) people with dementia - a walking mystery; (2) we need to go along with them, but it is challenging; and (3) if we know, we can care for them in a better way. Conclusion: The findings revealed a wide range of differences in attitude towards and inadequate knowledge of dementia among nursing staff. However, their overall attitudes toward people with dementia was positive.

(c) 2021 The Author(s)

Published by S. Karger AG, Basel

\section{Introduction}

It is estimated that 900 million people worldwide are 60 years or older, and the number of these older people is forecasted to increase. The vast majority of this growth will occur in low- income (239\% increase) or middle-income (185\% increase) countries [1]. In India, the number of older people is growing rapidly [2], making India the country with one of the highest number of older people in the world [3]. Increased life expectancies will lead to an increased need for care and support of older people [4]. 
Furthermore, due to the rapid increase in the number of older people in need of care, there is limited time to develop services to respond to the aging population and their needs [5].

In 2015, a total of 46.8 million people worldwide were estimated to be living with dementia, and this number will almost double every 20 years to 74.7 million by 2030 and 131.5 million by 2050 [1]. Dementia is not an inevitable accompaniment of normal ageing but it is more common among older people as ageing of the brain is a major risk factor. The incidence increases exponentially after the age of 60 years, doubling with every 6.3-year increase in age from 3.9 per 1,000 person-years at age 60-64 years to 104.8 per 1,000 person-years at age $90+$ years [ 1 , $6]$. In 2015 , about $6 \%$ of all people with dementia lived in low- or middle-income countries; however, this proportion is expected to increase to $68 \%$ by 2050 [1].

In 2010, it was estimated that nearly 3.7 million Indians had dementia. This number is estimated to increase by $300 \%$ by 2040 [1]. Despite this huge increase, dementia as a disease is still not widely recognized in India unless it is fairly advanced [7-9]. Furthermore, the condition is seldom recognized as an organic brain syndrome or a medical condition $[1,10]$. Early signs of dementia are often interpreted by families as a part of normal ageing or as depressive symptoms and they are therefore neglected by both families and health policy makers [7-9].

According to the World Alzheimer Report [11], 23.4\% of Indians with dementia make an effort to keep their dementia a secret when meeting with other people, and $7.4 \%$ of healthcare personnel do the same. As many as $24.3 \%$ of the general public perceives people with dementia as "dangerous."

A systematic review by Evripidou et al. [12] exploring nurses' knowledge of and attitudes toward dementia reported a lack of knowledge, communication skills, management strategies, and confidence in provision of care. However, intervention studies have suggested that both knowledge of and attitudes toward dementia improve after attending training programs.

Brodaty et al. [13] investigated the attitudes of nursing home staff toward residents, strain related to dementia, and satisfaction with work and their associations with demographic, occupational, and behavioral disturbances. The researchers found that the nursing home staff s most prevalent perceptions of residents with dementia were that they were "anxious, have little control over their difficult behavior, are unpredictable, lonely and frightened/ vulnerable." The complexity of caring for people with dementia could be one reason why care staff in general have a negative attitude toward people with dementia [14], and nursing students have reported negative experiences with these patients during their clinical practice [15]. Another reason why students may have negative experiences when caring for people with dementia could be that nursing teachers lack knowledge about the disease [16]. Studies have even reported that Indian nursing students know next to nothing about how to care for this group of patients $[17,18]$. These findings are cause for concern since it is expected that nearly all nursing students will have to work with older people with dementia after finishing their studies in India [19].

Studies have shown that training of healthcare professionals about dementia can help them to deal effectively with behavioral problems and improve healthcare delivery [20, 21]. However, the Dementia India Report [22] stated that there was no special emphasis on the diagnosis and management of people with dementia in the training of healthcare professionals in India.

The aim of this study was therefore to explore the knowledge of and attitudes toward dementia among nursing staff working in residential care facilities for older people in India.

\section{Method}

This study had an explorative and descriptive qualitative design and used focus group interviews for data collection, and it is reported in accordance with Consolidated Criteria for Reporting Qualitative Research (COREQ) [23].

\section{Setting and Participants}

Twelve participants, i.e., 8 nurses and 4 care assistants, all female, with an average age of 45.5 years (range $22-82$ years), were recruited to take part in the focus group interviews. The participants represented 6 residential care facilities for older people in different parts of India run by Catholic religious orders. The criteria for inclusion were: knowledge of the English language and experience working with older people. The participants' experience working with older people ranged from 5 months to 20 years, with an average of 4.5 years.

\section{Data Collection}

The demographic data collected from the participants included age, level of education, and years of experience working with old people.

Two focus group interviews consisting of 6 participants in each group were conducted in November 2018 by the study's first (B.S.S.) and last (A.G.) authors. The researcher used a semi-structured interview guide with questions focusing on the participants' knowledge of and attitudes toward dementia. These questions included, e.g.: What is your perception about dementia? What do you know about dementia - the symptoms, behaviors and needs? How is it to work with people with dementia? Is it different work- 
ing with elderly people with dementia compared to people without dementia? What do you think is the most challenging aspect of working with people with dementia? One interview lasted $50 \mathrm{~min}$ and the other $70 \mathrm{~min}$. Both interviews were audiotaped and transcribed.

\section{Analysis}

The focus group interviews were audio recorded and transcribed and checked for accuracy.

The participants' demographic information and experience working with old people were reported descriptively. A qualitative content analysis with an inductive approach, in line with Graneheim and Lundman [24], was performed to analyze the interviews, and we used in vivo coding. The aim of a content analysis is to manifest content and/or interpret for latent meanings of text, and it is performed by following 5 steps. In the first step, all 5 authors repeatedly and independently did an open reading of the interviews and then systematically divided the text into meaning units. The codes were then analyzed for shared content by the first, second, and last authors. Third, the meaning units were condensed and coded independently by the first and second authors. In the next step, similar codes were organized and grouped into subcategories. In the fifth and last step, a theme that expressed the latent content of the text was determined. To ensure trustworthiness, the authors held several discussions through the entire analysis process about the themes revealed in the data until a consensus was reached.

\section{Findings}

The analysis revealed 3 dimensions of the participants' knowledge about and attitudes towards dementia, which comprised the following categories: (1) people with dementia - a walking mystery; (2) we need to go along with them, but it is challenging; and (3) if we know, we can care for them in a better way.

\section{People with Dementia - A Walking Mystery}

The participants' perceptions of residents with dementia were described in different ways. One participant described dementia as forgetfulness. This was reflected in the statement: "They forget about their past and remember just the here and now, and sometimes they forget that also." One of the challenge that follows forgetfulness is that the patients need to be reminded. "They don't take bath, they don't wash their clothes, and we have to remind them to do this, [as well as] bring them to eat and to do other activities." Another challenge described by one of the participants is that the patients often repeat the same questions. "They will repeat the same question again and again. They will ask [the question], and in the next moment, they will just forget [that they have asked it]." In addition, it was mentioned that the symptoms increase over time.

Being confused was also described as a symptom of dementia. This was explained as people with dementia not knowing where they are, searching for things, not knowing what day it is, and remembering their own names. One participant put it this way: "Very often they get confused... what they are doing and where they are going; they don't know what they have to do."

The participants described people with dementia as aggressive, angry, moody, fearful, and anxious. One participant said: "They sometimes even raise their hand [to us]. They're angry; they scream loudly as if they have fallen or they are in danger." People with dementia were also described as getting upset when they are contradicted and becoming irritable of fighting with others. As one participant said: "If we don't agree with them, then they get irritated... they get angry." At the same time, one participant expresses the difficulty she had in consoling people with dementia and indicated that the residents would cry. People with dementia were also described as imagining things and hallucinating. This was reflected in the statement: "They watch [us] from afar, and they say, 'see, they are talking about us only."”

Another mentioned aspect was that people with dementia are restless and keep moving. As one participant described it: "They will keep moving and will not sit quietly." According to another participant: "Sometimes they will get up in the night and dress up... they will pack up their things and say that they want to see their relatives and children at the mid of night." One referred to patients doing the same action repeatedly: "Sometimes they will repeat the same actions, like washing their hands. [They will] go back and wash their hands repeatedly."

The course of behavioral and psychological symptoms of dementia (BPSD) was described by some participants as part of the patient's past history. One participant said: "The past history of the family [is relevant], the family may not have given enough love and care - they might have been neglected."

Several participants thought that the symptoms of dementia could improve over time or even that people with 
dementia could be cured. This is reflected in statements such as: "A person who came to us was completely in dementia. With continuous care, treatment and follow-up, the person improved a lot, came back almost to normal." Another refers to a person with dementia becoming normal again. "They can be normal; they can be improved. I feel that with treatment, they can improve." One of the participants said that some people with dementia could be cured, while another said: "I don't think there is a treatment to cure it." The treatment referred to compromised the administration of psychotropic drugs, described by the participant as: "Psychiatric tablets... we were posted in psychiatric department. Some of the patients got tablets for depression and hallucinations." In addition, it is reported that: "Exercise and treatment can make them better."

People with dementia were described by some of the participants as not being normal. One participant said: "Normal people know what needs to be done next, but dementia patients don't know." After being challenged about this, the participant said: "No, they are not abnormal, but they are different." Finally, people with dementia were described as feeling lonely and abandoned. As one participant phrased it: "They are a walking mystery."

\section{We Need to Go along with Them, but It Is Challenging}

Spending time with the residents and listening to them was considered important in order to see the person. One participant explained that, to care for people with dementia, you need to constantly to keep an eye on them. Another participant said that the nursing staff have different qualifications and this influences the way they perceive the person: "We are all different and the way, how we perceive that person, no matter what their background, that's the magic."

Another aspect that was raised was the need to be patient and tolerant and to accept the person as he or she is. At the same time, one of the participants expresses that showing patience was challenging for her. Another said that both a lot of patience and endurance were required to care for people with dementia. One even stated that caring for people with dementia was not so easy because they do not always understand that the staff mean well. "We need to go along with them because they, eh, feel that they are right, so we cannot argue with them." One indicated that she tried to put herself in the situation of the person with dementia and that it is important to accept them as they are: "I put myself in the [position of the] person of the dementia... if I become like that... if my parents become like that, how will I accept them?"

The participants emphasized the importance of understanding people with dementia, which makes it easier to be patient. "Naturally, if you understand dementia, you need to develop more patience to understand the patient, and need to be humble and kind to take care of the patient and take responsibility of that person under your care." One participant said that once they accept and understand the person with dementia, it becomes easier to care for the person. At the same time, another participant felt that anybody could care for people with dementia. Moreover, caring for persons with dementia was seen as more complex than just medical care. "Being with them is more important than giving them medications, and sometimes, a nice hug does much more than anything."

Several participants reported that caring for people with dementia was time-consuming and that a lot of time was spent listening to the residents. However, one said that using the needed time is challenging as they are also engaged in other tasks that need their attention. One participant said what working with people with dementia was very different compared to working with other residents. However, another noted that she found it easier to work with people with dementia as they listened to what she said. In her experience, this is not the case with the other cognitively normal residents.

Having to deal with people who ask the same questions repeatedly was experienced as challenging. One participant said that she would become irritated, sometimes even angry, but that she did not show this in front of the resident. As one participant said: "To listen to them is [in my opinion] a big challenge because I get bored and they get irritated." Another said: "My challenge is to understand them and to treat them according to their condition, not according to my expectation."

It was sometimes necessary to raise their voice to keep the residents quiet. However, one participant stated that she sometimes realized in hindsight that she should have handled the situation differently: "As the days goes by, I realize the situations... that they are humans and we are supposed to handle the situations... and we are also humans. So, I have changed as a nurse."

The need, in some situations, to keep their distance from the patients was expressed by one of the participants: "I like going to the beach once a month." Another asked God for help and prayed for the residents, saying that doing this helped her understand the residents better. Sharing their experiences with the general practitio- 
ner, other members of staff, or friends was also helpful in coping with challenging situations. Humor is also used to cope with such situations. One said: "Being more humorous ... humor should be there."

Making up stories was used to make the person with dementia agree with staff. Some of the participants even said that they sometimes lied to get the person dressed in the morning. For example, one participant said: "First, I agree with them, then I say, 'This way is good,' so they listen to what I say." One indicated that she did not know how to handle such situations. In the beginning, she used to shout at the person with dementia, and she ignored them. Some of the participants stated that they got angry with the residents. However, one participant said that she felt bad when she got angry because the person with dementia do not realize why she was acting that way.

\section{If We Know, We Can Care for Them in a Better Way}

Several participants considered having knowledge about dementia as important, emphasizing that the knowledge helped them understand the patients better and even provide better care. This was reflected in statements such as: "If we know more about the condition, if we understand them, the reason and the signs and symptoms, whether it is dementia or something else, then I think we'll be able to understand them better and care for them in a better way." Another participant noted the consequences of a lack of knowledge. She said: "If I don't know what dementia is, I will not be able to understand a person. So, I should know what dementia is, why it is coming, for whom it is coming. Then... this way it is easy to deal with the person, understand them."

Several participants had obtained their knowledge of dementia by attending lectures, by reading books, and from the internet. One participant said: "Some knowledge we get from continuous nursing education (CNE) programs, which is a must for nurses in India these days." Another participant indicated that she learned from other staff, stating: "We learn from our seniors and get inspiration [from them]. In the beginning, I saw how my seniors were handling and treating the patients, and I got knowledge from them." The training the participants received and researched consisted of the diagnosis and symptoms of dementia, as well as an overall awareness of the disease. As one participant said: “...what to do, some technical things which we can use to deal with them."

In addition to having knowledge about dementia, a personal interest in the person living with dementia was

Nursing Staff's Knowledge and Attitudes toward Dementia expressed as essential. One participant said: “... not only knowledge, I feel... the person... if I have knowledge, if I don't have interests to take care of them ...so knowledge with a personal interest..."

\section{Discussion}

The aim of this study was to explore the knowledge of and attitudes toward dementia among healthcare personnel working in residential care facilities for older people in India. The findings revealed a wide range of differences in attitudes toward and inadequate knowledge about dementia among nursing staff. This notwithstanding, their overall attitude toward dementia was positive. These finding are consistent with a survey conducted in India by Strøm et al. [25], which revealed that nursing staff have a limited knowledge of dementia but their attitudes toward people living with dementia tend to be positive. Similar findings have been published by Biswas et al. [20], who reported a deficiency of knowledge about dementia among healthcare professionals in India. Further, an inadequate knowledge of dementia has also been reported among undergraduate nursing students in India. Nevertheless, the nursing students were reported to have positive attitudes toward people with dementia [17].

\section{Knowledge of Dementia}

The participants in our study described dementia by referring to symptoms such as forgetfulness and confusion. This is in line with previous studies of adults in Pakistan and India, where dementia was commonly understood to be a disease of forgetfulness, and this "forgetting" was a result of normal ageing and not a disease [26, 27]. This finding is supported by a systematic review of the public's knowledge and understanding of Alzheimer disease and dementia in which it was determined that lay people think that dementia is a part of the normal ageing process [28]. If dementia is considered to be a part of normal ageing and not due to a progressive brain disorder, this will have negative consequences for the planning and delivery of care, which in turn will increase the burden of care experienced by both family members and professional caregivers.

The participants in the present study described dementia by referring to people having BPSD, such as having hallucinations, imagining things, and being aggressive, angry, moody, fearful, anxious, and restless. Even though these symptoms are seen in many people with dementia during the course of the disease, the participants did not seem to understand the various underlying causes of 
BPSD. This is consistent with the understanding of healthcare personnel in Western countries about 40 years ago, when the possible underlying causes of BPSD were rarely questioned. Some participants in the present study believed that behavioral changes were related to the patients' past family history or, more precisely, that BPSD was due to not having received enough love and care in life. This notwithstanding, it was interesting to observe that the participants, to a certain degree, seemed to know how to handle people with BPSD by using humor to cope with challenging situations and making up stories (e.g., in order to get the person dressed in the morning instead of arguing). This begs the question: how do staff decide how to deal with BPSD? Are their decisions based on their knowledge, attitude, or experience? As this and other studies that included nurses and nursing students in India have reported, the knowledge about dementia is rather poor, so attitude and experience may play important roles in how the staff deal with people with BPSD in nursing homes.

The participants in the present study reported having received some training, mostly about dementia symptoms. This is positive as previous studies have shown that staff training in dementia care increases nurses' knowledge about dementia and has positive implications for the care of people with dementia $[12,29,30]$. This link between dementia-specific training and knowledge of dementia could well have positive implications for care in nursing homes if dementia-specific training were to be made mandatory. This need is supported by Biswas et al. [20], who argued that healthcare staff must be trained to recognize the symptoms of dementia, obtain sufficient knowledge to guide family members, and provide daily care of high quality to people with dementia.

Nevertheless, knowledge alone may not necessarily change the way staff approach and handle people with dementia [31]. To deliver qualitative dementia care in nursing homes, organization and leadership are important and necessary components [32]. Furthermore, healthcare staff should be given the opportunity to reflect on their own and others' practices. Reflective practice, which brings theory and practice together, provides staff with the ability to reflect on their actions so as to engage in a process of continuous learning [33]. By offering an organized reflective practice combined with formal training, healthcare staff will be able to learn from their own professional experiences.

It is well known that there is no cure for dementia [34]. However, several participants in our study thought that a person with dementia could improve over time and even become "normal again." This finding is con- sistent with the results of previous studies of Indian nursing students [17], Indian doctors and nurses [20], and Pakistani adults [26] in which the participants believed that symptoms may improve over time or even that the person could be cured. This is also in line with the study of Strøm et al. [25], who reported that, although the majority of the healthcare staff in 6 Indian nursing homes answered that Alzheimer disease could not be cured, about half of them said that people with dementia, in rare cases, could recover from the disease. Believing that dementia can be cured could have an impact on how the care is organized. In almost all people with dementia, the condition will progress, leading to more dependency in all activities of daily living, and these people will therefore need more and more daily care. This knowledge can have implications for the organization of work in nursing homes.

\section{Attitudes toward People Living with Dementia}

Even though some of the participants in our study described people with dementia as not being normal, they had an overall positive attitude toward them. This finding is in accordance with Poreddi et al. [17], who reported that Indian nursing students have an overall positive attitude toward people with dementia. An overall positive attitude toward dementia was also found in the study of Strøm et al. [25], in which Indian healthcare staff said that it was rewarding to work with people with dementia; however, they also indicated that they were not familiar with dementia, felt frustrated, and did not know how to help the people.

Several factors have been reported to affect the people's attitudes toward dementia. Kada et al. [35] found that nursing staff with more than 10 years of experience had significantly higher hopeful attitudes, while staff over 50 years of age reported significantly lower hopeful attitudes. The higher hopeful attitudes among those under 40 years of age compared to those over 40 years of age could be related to changes in nurses' training over the past 20 years, with a greater focus on person-centered care and less on traditional medical thinking in more recent times. These findings are in line with the results of a systematic review in which nurses under the age of 40 years indicated more hopeful attitudes [12]. The participants in our study had an average age of 45.5 years, with an average of 4.5 years of experience working with older people. It is interesting to note the overall positive attitude given the relatively old average age. This could be explained by the fact that all of the participants belonged to a religious, Catholic order emphasizing a value-based practice. 
Despite having positive attitudes toward people with dementia, the participants indicated that it was time consuming and difficult to work with people with dementia. Even though they sometimes had to raise their voice and needed to keep distance from the person with dementia to manage BPSD, they emphasized the importance of seeing and understanding the person (e.g., taking their perspective in difficult situations). Such an individual approach is consistent with findings from a study conducted in 6 nursing homes in India run by Catholic sisters, in which highly person-centered care was provided for the elderly [36]. This aligns with the principles of a personcentered care approach. One cornerstone of person-centered care is to treat the person as an individual by respecting their right to self-determination, mutual respect, and understanding [37]. The participants' understanding of the importance of being close to the person with dementia, being patient and tolerant, and accepting the person are elements consistent with a person-centered approach toward the care of people with dementia.

\section{The Relationship between Knowledge and Attitude}

When looking at the relationship between knowledge and attitude, one question that arises is whether knowledge affects the attitude or vice versa or whether these 2 elements are not related to each other. Even though it is difficult to know how knowledge and attitudes toward dementia relate to one another, previous studies have reported that attending education and training programs about dementia improves staffs' attitudes toward caring for people with dementia [30]. Furthermore, staff who have adequate knowledge of dementia have also been reported to have a positive attitude toward dementia $[38,39]$.

Another question to ask is whether there are some basic elements of the human attitude that do not depend on knowledge but instead relate to the person handling the situation and what they perceive to be right. The elderly in Indian culture are generally obeyed and treated with respect and dignity by the family and community members. Having close relations with elderly members of one's family is a part of Indian culture. The majority of young people are accustomed to living with their grandparents from time to time from birth. They grow up appreciating and loving them and learn to adjust to living with elderly family members [40]. This cultural phenomenon could be one of the reasons why Indian nurses have positive attitudes toward elderly residents with dementia despite their lack of requisite knowledge about dementia.

Nursing Staff's Knowledge and Attitudes toward Dementia

\section{Strengths and Limitations}

This study had some limitations. The fact that all of the participants were Catholic, religious sisters working in their own nursing homes could have affected the findings. However, there are relatively few nursing homes in India, and most are run by religious orders or other private organizations, so we cannot know whether other nurses could have answered differently compared to the participants of the present study. A further limitation is the design of this study and the small number of participants. However, as the findings of the focus group interviews were in line with those of larger surveys, we suggest that the qualitative study design and the small number of participants had no major influence on the results.

\section{Conclusions}

To the best of our knowledge, this is the first and only study exploring the knowledge and attitudes of nursing staff toward dementia in an Indian residential care setting using a qualitative design. Despite the limitations of this study, the findings could have important implications for future dementia care in India.

The overall findings of the present study emphasize the urgent need to improve the knowledge of dementia among nursing staff in India. The wide range of differences in attitude toward and inadequate knowledge of dementia among nursing staff emphasizes the need to provide organized dementia training, including the possibility of reflective practice. This, together with the staffs' positive attitudes toward dementia, could give hope to the growing number of people who will be in need of highquality dementia care in India in the years to come.

\section{Acknowledgement}

We would like to express our gratitude to the nursing staff in the 6 nursing homes in India for their contribution to this study.

\section{Statement of Ethics}

This study was approved by the Norwegian Social Science Data Services (NSD). As no residents were interviewed or examined, ethical approval was not required according to the Norwegian act of medical and health research and as confirmed by the NSD (reference No. 57526).

However, ethical approval was obtained from the board of management in each residential care facility in India. The sampling was based on voluntary participation. The participants were

Dement Geriatr Cogn Disord Extra 2021;11:29-37 DOI: $10.1159 / 000514092$ 
informed about this study, and informed consent was obtained after the facilitator had provided information about this study. The need to obtain approval from the Health Ministry's Screening Committee of India was considered; however, we were informed that only biomedical and health research conducted after September 2019 required ethical approval.

\section{Conflict of Interest Statement}

The authors declare no conflict of interests.

\section{Funding Sources}

None.

\section{Author Contributions}

Benedicte Sørensen Strøm, Hilde Lausund, Knut Engedal, Anne Marie Mork Rokstad, and Alka Goyal contributed to the design of the research and analysis of the data, while Alka Goyal and Benedicte Sørensen Strøm collected the data.

\section{References}

1 Prince M, Wimo A, Guerchet MM, Ali GC, Wu YT, Prina M. World Alzheimer report 2015: the global impact of dementia - an analysis of prevalence, incidence, cost and trends. London: Alzheimer's Disease International; 2015.

2 Shaji KS. Dementia care in developing countries: the road ahead. Indian J Psychiatry. 2009 Jan;51 Suppl 1:S5-7.

3 Gupta R. Systems perspective: understanding care giving of the elderly in India. Health Care Women Int. 2009 Dec;30(12):1040-54.

4 Ugargol AP, Hutter I, James KS, Bailey A. Care needs and caregivers: associations and effects of living arrangements on caregiving to older adults in India. Ageing Int. 2016;41(2): 193-213.

5 Chatterji S, Kowal P, Mathers C, Naidoo N, Verdes E, Smith JP, et al. The health of aging populations in China and India. Health Aff (Millwood). 2008 Jul-Aug;27(4):1052-63.

6 Shaji KS, Jithu VP, Jyothi KS. Indian research on aging and dementia. Indian J Psychiatry. 2010 Jan;52(7 Suppl 1):S148-52.

7 Sinha P, Das P, Sharma N, Bhattacharjee S. A case of Hansen's disease presenting with sulfone syndrome and hemolytic anemia. Indian J Public Health. 2011;55(2):67-9.

8 Rao GN, Bharath S. Cost of dementia care in India: delusion or reality? Indian J Public Health. 2013 Apr-Jun;57(2):71-7.

9 Alphonso T, Krishnamoorthy ES, Gomes K. Caregiving for dementia: global perspective and transcultural issues. In: Ennapadam S, Krishnamoorthy MJP, Cummings JL, editors. Dementia: A global approach. 1st ed. New York: Cambridge University Press; 2010.

10 Shaji KS, Smitha K, Lal KP, Prince MJ. Caregivers of people with Alzheimer's disease: a qualitative study from the Indian 10/66 Dementia Research Network. Int J Geriatr Psychiatry. 2003 Jan;18(1):1-6.

11 Alzheimer's Disease International. World Alzheimer report 2019: attitudes to dementia. London: Alzheimer's Disease International; 2019.
12 Evripidou M, Charalambous A, Middleton N, Papastavrou E. Nurses' knowledge and attitudes about dementia care: systematic literature review. Perspect Psychiatr Care. 2019 Jan;55(1):48-60.

13 Brodaty H, Draper B, Low LF. Nursing home staff attitudes towards residents with dementia: strain and satisfaction with work. J Ady Nurs. 2003 Dec;44(6):583-90.

14 Moyle W, Murfield JE, Griffiths SG, Venturato L. Care staff attitudes and experiences of working with older people with dementia. Australas J Ageing. 2011 Dec;30(4):186-90.

15 Robinson A, Cubit K. Caring for older people with dementia in residential care: nursing students' experiences. J Adv Nurs. 2007 Aug; 59(3):255-63.

16 Saini R, Alagh P, Carpenter B. Nurses and Alzheimer's disease: a holistic perspective. Indian J Public Health. 2012 Oct-Dec;56(4): 318-9.

17 Poreddi V, Carpenter BD, Gandhi S, Chandra $\mathrm{R}$, GandhiSuresh BadaMath S. Knowledge and attitudes of undergraduate nursing students toward dementia: an Indian perspective. Invest Educ Enferm. 2015 Dec;33(3): 519-28.

18 Prince M; 10/66 Dementia Research Group. Care arrangements for people with dementia in developing countries. Int J Geriatr Psychiatry. $2004 \mathrm{Feb} ; 19(2): 170-7$.

19 Kaur S, Kumar A, Kaur B, Rani B, Ghai S. Knowledge and attitude regarding care of elderly among nursing students: an Indian perspective. J Nurs Care. 2014;3(3).

20 Biswas A, Shantanu D, Sujit S, Uttam M, Manabendra M, Shyamal KD. Knowledge about dementia among doctor and nurses in a medical college hospital in India. J Alzheimers Parkinsonism Dement. 2017;2(1):1-9.

21 Spector A, Revolta C, Orrell M. The impact of staff training on staff outcomes in dementia care: a systematic review. Int J Geriatr Psychiatry. 2016 Nov;31(11):1172-87.

22 Alzheimer's and Related Disorders Society of India. The Dementia India Report: prevalence, impact, costs and services for dementia. New Delhi: ARDSI; 2010.
23 Tong A, Sainsbury P, Craig J. Consolidated criteria for reporting qualitative research (COREQ): a 32-item checklist for interviews and focus groups. Int J Qual Health Care. 2007 Dec;19(6):349-57.

24 Graneheim UH, Lundman B. Qualitative content analysis in nursing research: concepts, procedures and measures to achieve trustworthiness. Nurse Educ Today. 2004 Feb;24(2):105-12.

25 Strøm BS, Engedal K, Andreassen L. Nursing staff's knowledge and attitudes toward dementia: a pilot study from an Indian perspective. Dement Geriatr Cogn Disord Extra. 2019 Oct;9(3):352-61.

26 Farina N, Zaidi A, Willis R, Balouch S. Attitudes, knowledge and beliefs about dementia: focus group discussions with Pakistani adults in Karachi and Lahore. Ageing Soc. 2019;40: $1-16$.

27 Patel V, Prince M. Ageing and mental health in a developing country: who cares? Qualitative studies from Goa, India. Psychol Med. 2001 Jan;31(1):29-38.

28 Cahill S, Pierce M, Werner P, Darley A, Bobersky A. A systematic review of the public's knowledge and understanding of $\mathrm{Al}$ zheimer's disease and dementia. Alzheimer Dis Assoc Disord. 2015 Jul-Sep;29(3):255-75.

29 Smyth W, Fielding E, Beattie E, Gardner A, Moyle W, Franklin S, et al. A survey-based study of knowledge of Alzheimer's disease among health care staff. BMC Geriatr. 2013 Jan;13(1):2.

30 Foreman P, Gardner I. Evaluation of education and training of staff in dementia care and management in acute settings. Melbourne: Department of Human Services; 2005. p. 87.

31 Titler MG, Herr K, Schilling ML, Marsh JL, Xie XJ, Ardery G, et al. Acute pain treatment for older adults hospitalized with hip fracture: current nursing practices and perceived barriers. Appl Nurs Res. 2003 Nov;16(4):211-27.

32 Rokstad AM, Vatne S, Engedal K, Selbæk G. The role of leadership in the implementation of person-centred care using Dementia Care Mapping: a study in three nursing homes. J Nurs Manag. 2015 Jan;23(1):15-26. 
33 Clift R, Loughran J. Reflective practice: Donald Schön. New York: Teachers College Ptress; 2014. p. 700-2.

34 Engedal K, Haugen PK, Brækhus A. Demens: sykdommer, diagnostikk og behandling. Tønsberg: Forl. aldring og helse akademisk; 2018.

35 Kada S, Nygaard HA, Mukesh BN, Geitung JT. Staff attitudes towards institutionalised dementia residents. J Clin Nurs. 2009 Aug; 18(16):2383-92.
36 Strøm BS, Engedal K, Rokstad AM. Engagement in everyday activities among people living in Indian nursing homes: the association with person-centredness. Dement Geriatr Cogn Disord Extra. 2020 Jan;10(1):13-26.

37 McCormack B, McCance T. Person-centred practice in nursing and health care. Oxford: Wiley; 2017.
38 Sullivan K, O'Conor F. Providing education about Alzheimer's disease. Aging Ment Health. 2001 Feb;5(1):5-13.

39 Chang CY, Hsu HC. Relationship between knowledge and types of attitudes towards people living with dementia. Int J Environ Res Public Health. 2020 May;17(11):E3777.

40 Chadha NK. Understanding intergenerational relationships in India. J Intergenerational Relationships. 2004;2(3-4):63-73. 